\title{
Design and Evaluation of the Environmental Outreach Activity for Middle School Students
}

\author{
Sarah M. Harris, ${ }^{\mathrm{a}, \mathrm{b}}$ Katie L. Peterson, ${ }^{\mathrm{c} \ddagger}$ Kate M. Bailie, ${ }^{\mathrm{a} \dagger}$ Chris D. Tower, ${ }^{\mathrm{d}}$ Brian K. Rundle, ${ }^{\mathrm{e}}$ Travis R. \\ Ricks, ${ }^{f}$ and Valérie C. Pierre ${ }^{\mathrm{g} *}$ \\ ${ }^{a}$ Department of Chemistry, State University of New York Oswego, Oswego, NY 13126; bepartment of Chemistry \& Biochemistry, \\ Benedictine College, Atchison, KS 66002; ${ }^{\circ}$ Department of Chemistry, Bemidji State University, Bemidji, MN, 56601; ${ }^{\mathrm{d} B e m i d j i}$

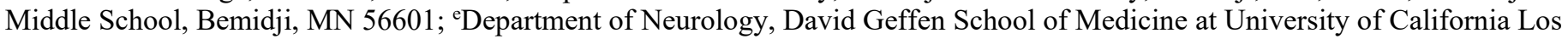 \\ Angeles, Los Angeles, CA 90095; fDepartment of Psychology, Bemidji State University, Bemidji, MN, 56601; ' ${ }^{\text {Department of }}$ \\ Chemistry, University of Minnesota, Minneapolis, MN, 55455.
}

\section{SUPPORTING INFORMATION}

\section{Table of Contents}

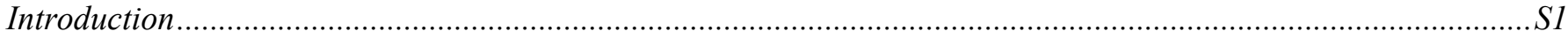

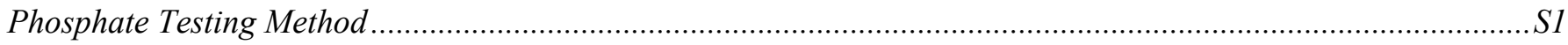

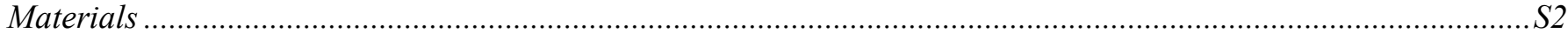

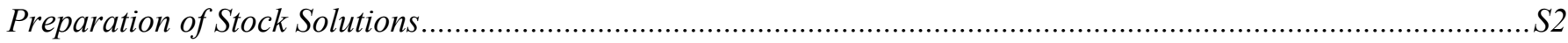

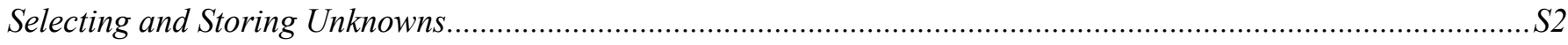

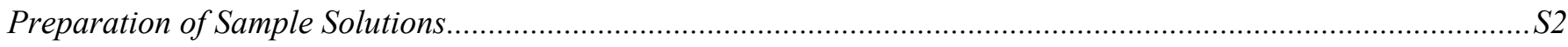

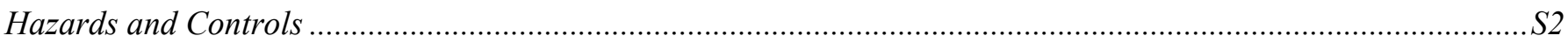

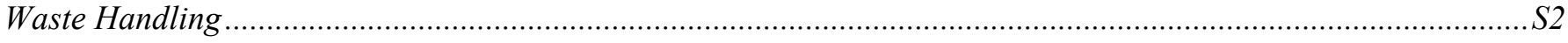

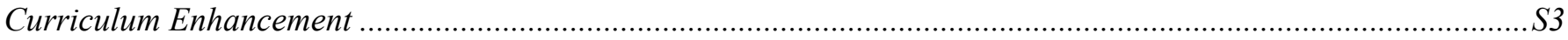

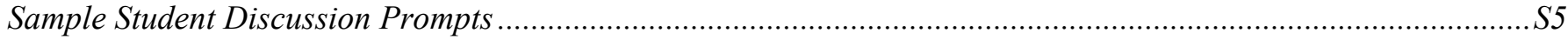

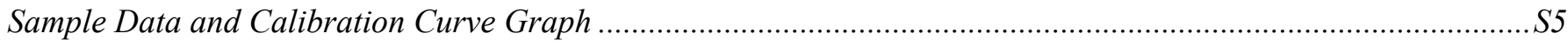

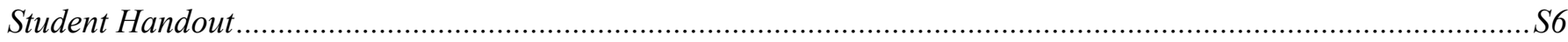

\section{Introduction}

The following documents are provided to facilitate the use of a phosphate testing Environmental Protection Agency protocol for $6^{\text {th }}$ grade outreach and/or education.

\section{Phosphate Testing Method}

This method was adapted from the EPA's Method 365.3: Phosphorus, All forms (Colorimetric, Ascorbic Acid, Two Reagent) U.S. Environmental Protection Agency, Washington, DC. Available at https://www.epa.gov/sites/production/files/2015-08/documents/method_365-3_1978.pdf 


\section{Materials}

Preparation:

1. $\mathrm{KH}_{2} \mathrm{PO}_{4}(0.0439 \mathrm{~g})$

2. Ammonium Molybdate $(2 \mathrm{~g})$

3. Antimony Potassium Tartrate $(0.05 \mathrm{~g})$

4. Ascorbic Acid (30 g)

5. Concentrated Sulfuric Acid $(38.25 \mathrm{~mL})$

6. Acetone $(1 \mathrm{~mL})$

7. $100 \mathrm{~mL}$ volumetric flasks (1)

8. $25 \mathrm{~mL}$ volumetric flasks (6 per experiment)

9. $250 \mathrm{~mL}$ volumetric flasks (2)

10. $500 \mathrm{~mL}$ volumetric flask (1)

11. $1000 \mathrm{~mL}$ volumetric flask (1)

12. Metal Spatula (4)

13. Weighing Paper/weighing boats

14. $20 \mathrm{~mL}$ volumetric pipette (1)

15. $15 \mathrm{~mL}$ volumetric pipette (1)

16. $10 \mathrm{~mL}$ volumetric pipette (1)

17. $5 \mathrm{~mL}$ volumetric pipette (1)

18. $100 \mathrm{~mL}$ graduated cylinder (1)

19. $50 \mathrm{~mL}$ graduated cylinder (1)
For student experiment:

20. 4 stock solutions

21. Unknown samples (local surface water, tap water, etc.) stabilized with acid

22. Student Experiment Guides (1 per student)

23. UV-vis spectrophotometer ( $\sim 2$ for 30 students)

24. Plastic cuvettes ( $\sim 8$ per group)

25. Software and Instruction Sheets $(\sim 1$ per group $)$

26. Kimwipes

27. $50 \mathrm{~mL}$ Beaker ( 8 per group)

28. Stirring rods (1 per sample)

29. Plastic Transfer pipettes ( 1 per sample, $\sim 8$ per group)

30. $1000 \mathrm{~mL}$ micropipette and tips (1 box/instrument per group)

31. DI Water bottle (1 per group)

32. Nitrile Gloves (1 pair per student)

33. Goggles (1 per student)

34. Plastic Rulers (1 per student)

35. Hazardous Waste Containers

\section{Preparation of Stock Solutions}

Four stock solutions are needed.

1a. Preparation of $100 . \mathrm{mg} P / L$ solution:

(Allows for ten $1.0 \mathrm{mg} P / L$ solutions)

A $100 . \mathrm{mg} \mathrm{P} / \mathrm{L}$ stock solution was prepared by dissolving previously dried (at $105^{\circ} \mathrm{C}$ for 1 hour)

$\mathrm{KH}_{2} \mathrm{PO}_{4}(0.0439 \mathrm{~g}, 0.323 \mathrm{mmol})$ in DI water and diluting to $100.0 \mathrm{~mL}$ using a volumetric flask.

1b. Preparation of $1.0 \mathrm{mg} P / L$ solution

(Allows for 13 calibration curves)

A $1.0 \mathrm{mg} \mathrm{P} / \mathrm{L}$ solution was prepared by diluting the $100 . \mathrm{mg} \mathrm{P} / \mathrm{L}$ solution hundred-fold $(10.0 \mathrm{~mL}, 0.00323$ $\mathrm{mmol}$ ) of the $100 \mathrm{mg} \mathrm{P} / \mathrm{L}$ stock solution was diluted with $\mathrm{DI}$ water to in a $1.0 \mathrm{~L}$ volumetric flask.

2. Preparation of $5.5 \mathrm{~N}$ Sulfuric acid

(Allows for 500 samples)

Sulfuric acid (38.25 mL of concentrated sulfuric acid) was slowly added to approximately $150 \mathrm{~mL}$ distilled water. The solution was allowed to cool and diluted to $250.0 \mathrm{~mL}$.

3. Preparation of Ammonium molybdate-antimony potassium tartrate $\left(6.472 \mathrm{mM}\left(\mathrm{NH}_{4}\right)_{6} \mathrm{Mo}_{7} \mathrm{O}_{24} \cdot 4 \mathrm{H}_{2} \mathrm{O}\right.$ and $0.030 \mathrm{mM} \mathrm{K}_{2} \mathrm{Sb}_{2}\left(\mathrm{C}_{4} \mathrm{H}_{2} \mathrm{O}_{6}\right)_{2}$ solution

(Allows for 125 samples - limiting) Ammonium molybdate $(2.000 \mathrm{~g}, 1.618 \mathrm{mmol})$ and antimony potassium tartrate $(0.050 \mathrm{~g}, 0.075 \mathrm{mmol})$ were diluted with DI water to $250.0 \mathrm{~mL}$ in a volumetric flask.

4. Preparation of Ascorbic acid (0.3407 M) solution

(Allows for 500 samples)

Ascorbic acid $(30.000 \mathrm{~g}, 0.17034 \mathrm{~mol})$ was diluted with DI water to $500.0 \mathrm{~mL}$ in a volumetric flask. After dilution, acetone $(1.0 \mathrm{~mL})$ was added to the $500.0 \mathrm{~mL}$ aqueous ascorbic acid solution. 


\section{Selecting and Storing Unknowns}

Example unknowns include local surface waters (lakes or rivers), tap water, water from road ditches near agricultural fields, animal (fish) tanks. Treat water samples with concentrated sulfuric acid (2 mL per $1 \mathrm{~L})$ and refrigerate to prevent decomposition of the phosphate.

\section{Preparation of Sample Solutions}

Prepare standards and samples less than two hours before the event. (The stock solutions can be prepared several days before the event, but the sample preparation which combines them needs to be done right before each group of student begins). Each student group should have a set of six phosphate standards and several (1-3) unknowns. Preparation of each sample requires the addition of four components, which are labeled 1-4 in the following directions.

1. Standards and Unknowns.

a. Phosphate standard solutions are prepared from the $1.0 \mathrm{mg} \mathrm{P} / \mathrm{L}$ solution and diluted with DI water into a total volume of $25.0 \mathrm{~mL}$ in a volumetric flask (Table S1). The final concentrations of phosphate range from 0 to $1.0 \mathrm{mg} \mathrm{P} / \mathrm{L}$. Transfer the $25.0 \mathrm{~mL}$ standard to a $50 \mathrm{~mL}$ beaker.

b. For unknown water samples, add $25.0 \mathrm{~mL}$ of water samples to a $50 \mathrm{~mL}$ beaker.

To each of the standards and unknown samples,

2. Add $0.5 \mathrm{~mL}$ of sulfuric acid; final concentration $0.1 N(0.05 \mathrm{M})$.

3. Add $2.0 \mathrm{~mL}$ of ammonium molybdate- antimony potassium tartrate; final concentrations of $0.46 \mathrm{mM}$ and $0.0020 \mathrm{mM}$, respectively.

4. Add $1.0 \mathrm{~mL}$ of ascorbic acid (added by student); final concentration 12 $\mathrm{mM}$.

\section{Hazards and Controls}

- Students were provided with gloves and goggles to wear during the activity. They should also wear long pants, long sleeve shirts, and closed toe shoes.

Table S1: Preparation of phosphate standard solutions $(25.0 \mathrm{~mL}$ total volume) using $1.0 \mathrm{mg} \mathrm{P} / \mathrm{L}$ solution and DI water

\begin{tabular}{|c|c|}
\hline $\begin{array}{l}\text { Phosphate } \\
\text { Standard } \\
\text { Concentratio } \\
\mathrm{n}(\mathrm{mg} \text { P } / \mathrm{L})\end{array}$ & $\begin{array}{l}\text { Volume 1.0 } \\
\text { mg P/L } \\
\text { solution } \\
(\mathrm{mL})\end{array}$ \\
\hline 1.0 & 25 \\
\hline 0.8 & 20 \\
\hline 0.6 & 15 \\
\hline 0.4 & 10 \\
\hline 0.2 & 5 \\
\hline 0.0 & 0 \\
\hline
\end{tabular}

- Solid sodium bicarbonate (baking soda) was used to neutralize any spilled solutions containing the dilute sulfuric acid.

- In order to limit the major hazard, the concentration of strong acid was reduced by half from $11 \mathrm{~N}$ to $5.5 \mathrm{~N}$. The stock sulfuric acid stock is $5.5 \mathrm{~N}$ and should only be handled by the college student volunteers, not the middle school student participants.

- Complete hazards and precautionary measures can be found in the individual safety data sheets (SDS) for each chemical. Collectively, these chemicals should not be ingested and may cause irritation to the skin or eyes. If sample contact skin, flush with warm water for $15 \mathrm{~min}$. No food or drinks were allowed in the lab and the final solutions were disposed of as hazardous waste.

\section{Waste Handling}

The following categories of waste were collected:

1. All prepared samples, plus the excess phosphate stocks and ammonium molybdate-antimony potassium tartrate stock. Processed according to local hazardous waste guidelines. (Health: 2, Flammability: 1)

2. Sulfuric acid stock. Neutralized by adding baking soda, diluted with water, and poured down the drain.

3. Ascorbic acid with acetone was poured down the drain.

For further information on waste disposal pick up or drop off, fees, and proper adherence to local regulations contact a college or university near you. 


\section{Curriculum Enhancement}

Table S2. Connections to the Next Generation Science Standards (NGSS).

STANDARD: MS-PS1: Matter and its Interactions

PERFORMANCE EXPECTATION: MS-PS1-2: Analyze and interpret data on the properties of substances before and after the substances interact to determine if a chemical reaction has occurred.

https://www.nextgenscience.org/pe/ms-ps1-2-matter-and-its-interactions

\section{Dimension}

\section{Classroom Connection}

\section{Science and Engineering Practice}

Analyzing and Interpreting Data

- Analyze and interpret data to determine similarities and differences in findings.

\section{Disciplinary Core Idea (DCI)}

PS1.A: Structure and Properties of Matter

- Each pure substance has characteristic physical and chemical properties (for any bulk quantity under given conditions) that can be used to identify it.

PS1.B: Chemical Reactions

- Substances react chemically in characteristic ways. In a chemical process, the atoms that make up the original substances are regrouped into different molecules, and these new substances have different properties from those of the reactants.

\section{Crosscutting Concept}

Patterns

- Macroscopic patterns are related to the nature of microscopic and atomic-level structure.
Students collect absorbance data.

Students graphically analyze data that correlates the concentration of phosphate to absorbance.

Students use a physical property (blue color) of the phosphomolybdate complex to measure its concentration.

Students perform a chemical reaction by adding the reducing agent ascorbic acid to the reaction mixture forming the phosphomolybdate complex. Students observe the color change (blue color) associated with this chemical transformation.

Students evaluate the relationship between concentration of phosphate and phosphomolybdate complex at the atomic level and the macroscopic property of color intensity.

STANDARD: MS-LS2: Ecosystems: Interactions, Energy, and Dynamics

PERFORMANCE EXPECTATION: MS-LS2-1: Analyze and interpret data to provide evidence for the effects of resource availability on organisms and populations of organisms in an ecosystem. https://www.nextgenscience.org/pe/ms-ls2-1-ecosystems-interactions-energy-and-dynamics

\section{Dimension}

Science and Engineering Practice

Analyzing and Interpreting Data

- Analyze and interpret data to provide evidence for phenomena.

\section{Disciplinary Core Idea (DCI)}

LS2.A: Interdependent Relationships in Ecosystems

- Organisms, and populations of organisms, are dependent on their environmental interactions both with other living things and with nonliving factors.

- In any ecosystem, organisms and populations with similar requirements for food, water, oxygen, or other resources may compete with each other for limited resources, access to which consequently constrains their growth and reproduction.

- Growth of organisms and population increases are limited by access to resources.

\section{Crosscutting Concept}

Cause and Effect

- Cause and effect relationships may be used to predict phenomena in natural or designed systems.

\section{Classroom Connection}

Students collect data on local water samples.

Students interpret data and identify relationships between the phosphate concentrations of water sources that are impaired versus those that are not.

Students discuss the relationships between phosphate concentration and trophic classification (or algae growth). Students relate the presence or absence of organisms in a lake water ecosystem to the amount of available phosphate resources.
Students predict the concentration of phosphate in water samples based on their trophic classification. 
Table S3. Expansion ideas that connect to additional Next Generation Science Standards (NGSS)

\begin{tabular}{|c|c|c|}
\hline Performance Expectation & Example student activity & $\begin{array}{l}\text { Science and } \\
\text { Engineering } \\
\text { Practice }\end{array}$ \\
\hline \multicolumn{3}{|l|}{ STANDARD: MS-PS1: Matter and its Interactions } \\
\hline $\begin{array}{l}\text { MS-PS1-1. Develop models to describe the atomic } \\
\text { composition of simple molecules and extended } \\
\text { structures. } \\
\text { https://www.nextgenscience.org/pe/ms-ps1-1- } \\
\text { matter-and-its-interactions }\end{array}$ & $\begin{array}{l}\text { Students build 3D molecular models (ball- } \\
\text { and-stick) depicting the chemical structure of } \\
\text { phosphate ions. }\end{array}$ & $\begin{array}{l}\text { Developing and } \\
\text { using models }\end{array}$ \\
\hline \multicolumn{3}{|c|}{ STANDARD: MS-LS2: Ecosystems: Interactions, Energy, and Dynamics } \\
\hline $\begin{array}{l}\text { MS-LS2-3. Develop a model to describe the cycling } \\
\text { of matter and flow of energy among living and } \\
\text { nonliving parts of an ecosystem. } \\
\text { https://www.nextgenscience.org/pe/ms-ls2-3- } \\
\text { ecosystems-interactions-energy-and-dynamics }\end{array}$ & $\begin{array}{l}\text { Students diagram the phosphate cycle. } \\
\text { Students use the phosphate cycle model to } \\
\text { predict how the use of excess mineral } \\
\text { fertilizers impact soluble phosphate levels and } \\
\text { algae growth in an aquatic system. }\end{array}$ & $\begin{array}{l}\text { Developing and } \\
\text { using models }\end{array}$ \\
\hline $\begin{array}{l}\text { MS-LS2-4. Construct an argument supported by } \\
\text { empirical evidence that changes to physical or } \\
\text { biological components of an ecosystem affect } \\
\text { populations. } \\
\text { https://www.nextgenscience.org/pe/ms-ls2-4- } \\
\text { ecosystems-interactions-energy-and-dynamics }\end{array}$ & $\begin{array}{l}\text { Students examine lake water quality data } \\
\text { (phosphorus, chlorophyll, transparency, } \\
\text { trophic state, fish species) and construct an } \\
\text { argument for how increased phosphate } \\
\text { concentrations impact the ecosystem (algae } \\
\text { growth or fish species). }\end{array}$ & $\begin{array}{l}\text { Engaging in } \\
\text { argument from } \\
\text { evidence }\end{array}$ \\
\hline $\begin{array}{l}\text { MS-LS2-5. Evaluate competing design solutions for } \\
\text { maintaining biodiversity and ecosystem services. } \\
\text { https://www.nextgenscience.org/pe/ms-ls2-5- } \\
\text { ecosystems-interactions-energy-and-dynamics }\end{array}$ & $\begin{array}{l}\text { Students design and evaluate model } \\
\text { stormwater filters that reduce soil erosion and } \\
\text { nutrient run-off. }\end{array}$ & $\begin{array}{l}\text { Engaging in } \\
\text { argument from } \\
\text { evidence }\end{array}$ \\
\hline \multicolumn{3}{|l|}{ STANDARD: MS-ESS3: Earth and Human Activity } \\
\hline $\begin{array}{l}\text { MS-ESS3-3. Apply scientific principles to design a } \\
\text { method for monitoring and minimizing a human } \\
\text { impact on the environment. } \\
\text { https://www.nextgenscience.org/pe/ms-ess3-3- } \\
\text { earth-and-human-activity }\end{array}$ & $\begin{array}{l}\text { Students design and evaluate model } \\
\text { stormwater filters that reduce soil erosion and } \\
\text { nutrient run-off. }\end{array}$ & $\begin{array}{l}\text { Constructing } \\
\text { explanations and } \\
\text { designing solutions }\end{array}$ \\
\hline $\begin{array}{l}\text { MS-ESS3-4. Construct an argument supported by } \\
\text { evidence for how increases in human population } \\
\text { and per-capita consumption of natural resources } \\
\text { impact Earth's systems. } \\
\text { https://www.nextgenscience.org/pe/ms-ess3-4- } \\
\text { earth-and-human-activity }\end{array}$ & $\begin{array}{l}\text { Students make a claim about the relationship } \\
\text { between human population data and } \\
\text { phosphate fertilizer usage data and water } \\
\text { quality. Students evaluate if the evidence } \\
\text { supports cause-effect relationships that } \\
\text { connect increased population to the reduction } \\
\text { of phosphate mineral deposits or changes in } \\
\text { water quality. }\end{array}$ & $\begin{array}{l}\text { Engaging in } \\
\text { argument from } \\
\text { evidence }\end{array}$ \\
\hline
\end{tabular}




\section{Sample Student Discussion Prompts}

Method

1. Have you heard of ascorbic acid? (Ascorbic acid is Vitamin C!)

2. What is the chemical formula for phosphate? What is the molecular structure of phosphate?

3. How can you avoid air bubbles when using the micropipette?

4. Before measuring the absorbance of samples with the UV-Vis, the absorbance of only water was collected. This is called a blank. Why was a blank needed?

5. What happened when you added the ascorbic acid? Did a chemical reaction occur? How do you know?

6. What color light does something blue absorb? What colors do black and white absorb?

\section{Data Analysis/Graphing}

7. Which sample has the most phosphate? How do you know? (Correlate phosphate concentration to absorbance and blue color.)

8. Can you see phosphate ions? (Answer changes when in phosphomolybdate form.)

9. In this experiment, what are the independent and dependent variables? The independent variable is graphed on the $(x)$ axis, and the dependent variable is graphed on the $(y)$ axis.

10. How can one line be drawn that represents all the data points?

11. How can the absorbance data of the standards be used to find the concentration of phosphate in the unknown sample? Where does the unknown lie on the graph?

Application

12. Which unknown sample do you think will have the highest phosphate concentration? Why?

13. Some water samples came from impaired lakes and others did not. Do you expect this designation to affect the phosphate concentrations? How?

14. Is it bad to have phosphate in water? Why or why not?

15. How can phosphate change the type or number of organisms (like algae) living in the water?

16. If eutrophication occurs in a lake, what can you predict about the phosphate concentration?

17. What events lead to the creation of a dead zone?

18. Where does phosphate in the water come from? Where else can it be found? Is it always there?

19. How can we (humans) add phosphate to lake water? Why did we stop using phosphates in soaps?

20. How can the amount of phosphate in lakes be decreased?

\section{Sample Data and Calibration Curve Graph}

This is a sample graph of the absorbance versus the concentration of phosphate in the standards. Data may vary according to reaction conditions.

\begin{tabular}{|c|c|}
\hline $\begin{array}{c}\text { Phosphate } \\
\text { Concentration } \\
(\mathrm{mg} \mathrm{P} / \mathrm{L})\end{array}$ & at $650 \mathrm{~nm}$ \\
\hline 0.0 & 0.033 \\
\hline 0.2 & 0.074 \\
\hline 0.4 & 0.151 \\
\hline 0.6 & 0.236 \\
\hline 0.8 & 0.297 \\
\hline 1.0 & 0.366 \\
\hline
\end{tabular}

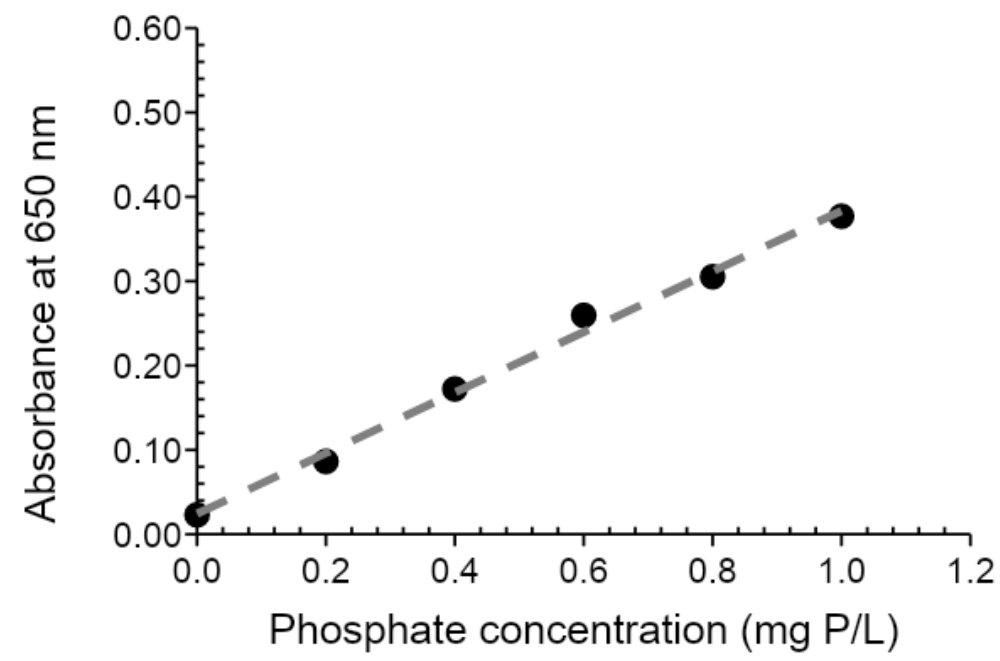




\section{Determination of phosphate in water samples}

Adapted from the EPA's Method 365.3: Phosphorus, All forms (Colorimetric, Ascorbic Acid, Two Reagent) U.S. Environmental Protection Agency, Washington, DC.

Are you ready? (Answer "yes" to all these questions.)

$\square$ Did you read the sample preparation and data collection procedure below?

$\square$ Do you agree to follow the safety rules?

$\square$ Are you wearing gloves and safety glasses?

\section{Procedure:}

\section{Sample preparation}

1. Gather the following solutions.

a. 6 phosphate standards: phosphate concentrations of $0.0-1.0 \mathrm{mg} \mathrm{P/L}$

b. 2 water samples with unknown phosphate concentrations

c. Ascorbic acid solution

2. Use the micropipette to add $1.00 \mathrm{~mL}$ of ascorbic acid to each sample.

3. Mix with a plastic stir rod. Rinse the stir rod with water in between samples.

4. Wait 5 minutes.

\section{Data collection}

Record the absorbance of the samples at $650 \mathrm{~nm}$ for standards and unknowns.

5. Transfer some of the sample to a plastic cuvette using a plastic transfer pipette.

6. Wipe the sides of the cuvette with a kimwipe.

7. Place the cuvette in the spectrophotometer so that the arrow on cuvette lines up with the arrow on the spectrophotometer.

8. Record the absorbance at $650 \mathrm{~nm}$ in the data table on the next page.

9. Pour the contents of the cuvette into the waste beaker.

10. Rinse the inside of the cuvette with DI water. Dry the outside with a kimwipe, and gently shake the cuvette with the open side facing down to dry the inside.

Repeat steps 5-10 for the remaining samples. 
Data:

Phosphate Standards

\begin{tabular}{|c|c|}
\hline $\begin{array}{c}\text { Phosphate Concentration } \\
(\mathrm{mg} \mathrm{P} / \mathrm{L})\end{array}$ & $\begin{array}{c}\text { Absorbance } \\
\text { at } 650 \mathrm{~nm}\end{array}$ \\
\hline 0.0 & \\
\hline 0.2 & \\
\hline 0.4 & \\
\hline 0.6 & \\
\hline 0.8 & \\
\hline 1.0 & \\
\hline
\end{tabular}

Graph your data

to find these.

(See the next page.)
Unknown Samples

Sample Name

Absorbance at $650 \mathrm{~nm}$
Phosphate Concentration (mg P/L) 
Safety:

- The phosphate standards and unknown samples contain sulfuric acid (100 mM), ammonium molybdate $(0.46 \mathrm{mM})$, antimony potassium tartrate $(0.02 \mathrm{mM})$, and ascorbic acid $(12 \mathrm{mM})$.

- These chemicals are harmful if swallowed. Contact with skin or eyes may cause irritation. Students should wear gloves, goggles, long pants, long sleeve shirts, and closed toe shoes.

- All liquid waste from the sample should be disposed of as hazardous waste.

Data interpretation and graphing:

\section{Graph the data}

11. Graph the absorbance versus the phosphate concentrations for the standards.

a. The concentration of phosphate is the independent variable ( $x$-axis).

b. The absorbance at $650 \mathrm{~nm}$ is the dependent variable ( $y$-axis).

12. Draw a "best fit" line through your data points using a ruler. The line doesn't have to connect or touch all the points.

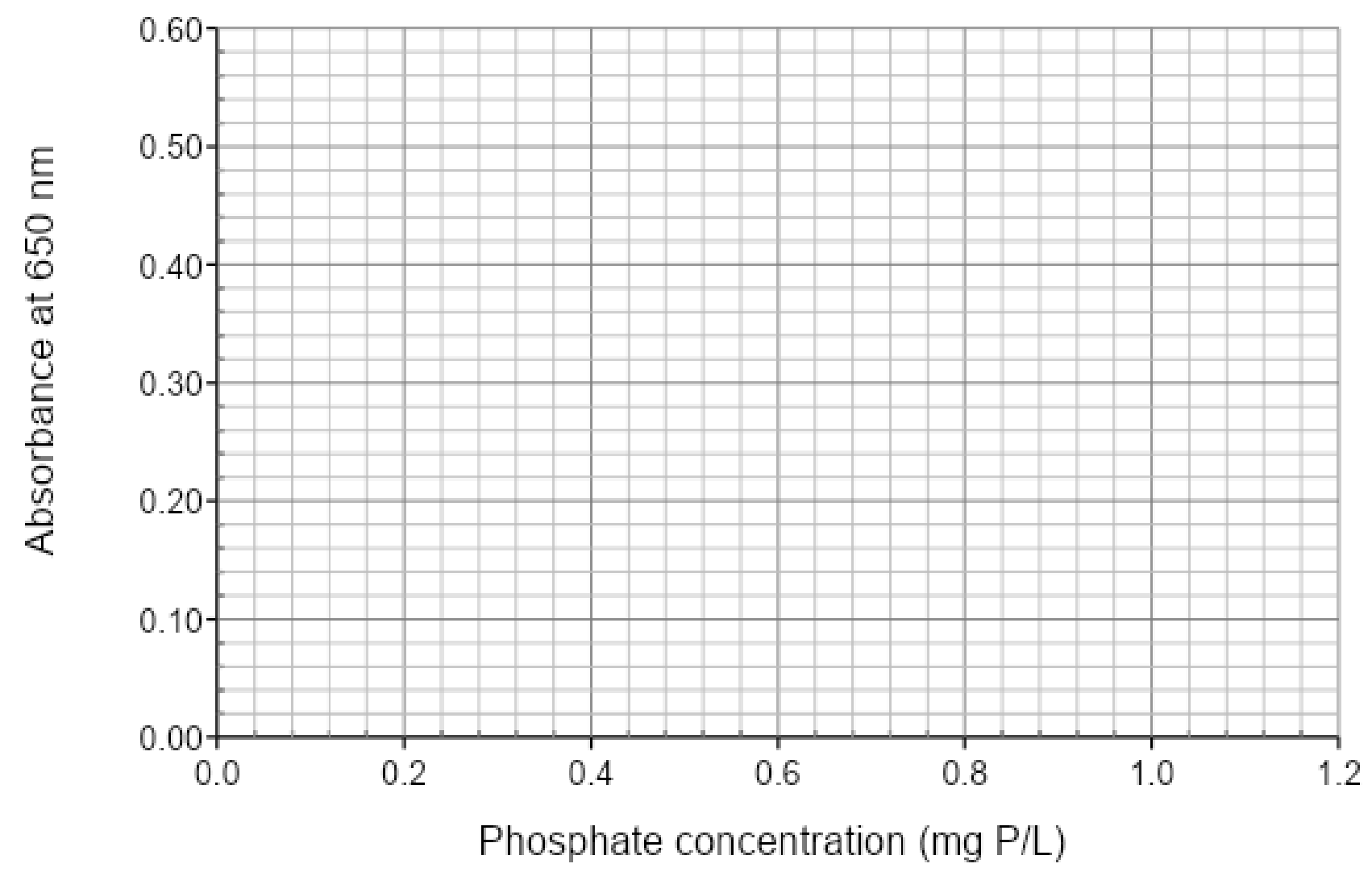




\section{Graphically determine concentration in the unknown}

13. Use the graph to find the concentration of phosphate in a sample.

a. Find the measured absorbance value of the unknown on the $y$ axis.

b. Use a ruler to draw a straight, horizontal line that intersects with the diagonal line of the data points.

c. From the point where the two lines intersect, draw a straight, vertical line using a ruler to the $x$ axis.

d. The value of where this line hits the $x$ axis is the concentration of phosphate in the sample.

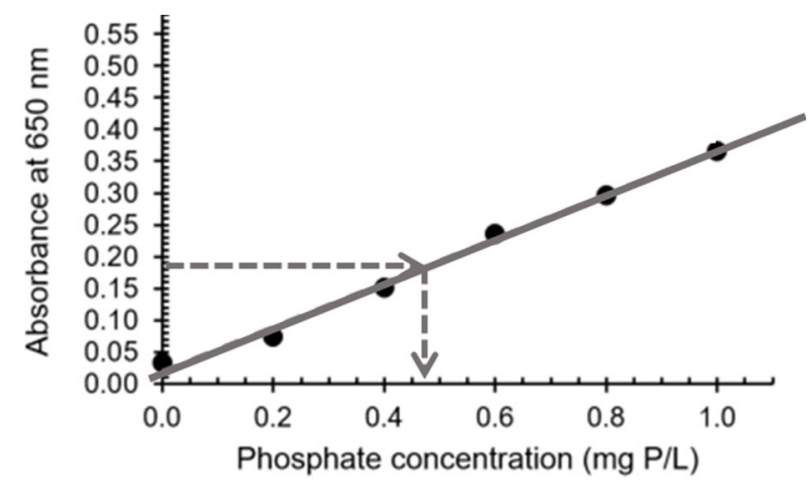

